\title{
The SMNH implementation framework for districts
}

The Safe Motherhood Demonstration Project

Follow this and additional works at: https://knowledgecommons.popcouncil.org/departments_sbsr-rh How does access to this work benefit you? Let us know!

\section{Recommended Citation}

"The SMNH implementation framework for districts," Safe Motherhood Policy Alert. Nairobi: Population Council, 2005. 


\section{The SMNH Implementation Framework for Districts}

7 his implementation framework was developed as a result of lessons learnt and approaches 1 used during the SMDP in Western Province 2000 - 2004. Commitment by the DHMT to improve SMNH services is a pre-requisite of this process; the process will involve time and commitment. All the components require cooperation and support at provincial and national level. The diagram outlines six stages: preparatory; rapid appraisal; analysis; planning the intervention; implementation; and evaluation.

\section{Step 1: Preparation}

Consultation during the District Health Stakeholders Forum could include: DHMT/DHMB, Facility staff, NGOs, Faith Based Organisations, Community Based Organisations, other ministries, community members, users of facilities to identify needs and views on SMNH services. An Inter-sectoral SMNH team could be nominated.

\section{Step 2: SM Rapid Appraisal}

Rapid appraisal carried out at district and facility levels.

\section{Step 3: Analysis}

Analyse information gained from the RAT within the district and incorporated into district plans

\section{Step 4: Devise Interventions}

E.g. Infrastructure, Equipment and supplies, Training programme, Community involvement, Vulnerable groups included. M and E strategy

\section{Step 5: Implementation}

Strengthen management structures and support system for SMNH

Strengthen provider competency and skills: Skilled attendance at birth

\section{Step 6: Evaluation}

Evaluate the interventions using the SM RAT yearly prior to next annual plan development. (Audit cycle)
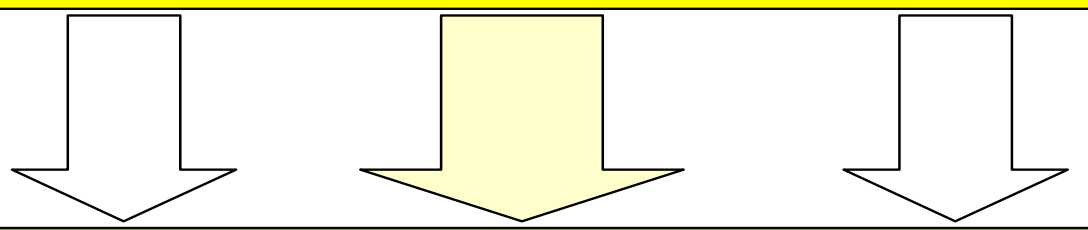

\section{Results}

Improvement in SMNH services,

Increase in utilisation of health services

Community Action 


\section{A RAPID APPRAISAL TOOL FOR SAFE MOTHERHOOD PROGRAMMES}

The development of a Safe Motherhood Rapid Appraisal Tool (SM RAT) has been an important outcome of the DFID Western Province Safe Motherhood Demonstration project 2000 - 2004.

The intervention in Western Province was based on addressing resource and skills gaps in service provision which were identified by a situation analysis carried out in each district. Through the introduction of training programmes tailored to staff needs, ensuring basic equipment and drugs were available, and ensuring greater community involvement, safe motherhood services have been improved in Western Province. The situation analysis exercise was refined during the project, resulting in the development of the safe motherhood rapid appraisal tool (SM RAT).

\section{Safe Motherhood Rapid Appraisal Tool (SM RAT)}

- An effective means of identifying resource and skills gaps in the provision of SMNH services: facilities, equipment, commodities and drugs; staff, skills mix, and training needs; community resources

- Findings can be used to define an implementation strategy (to be incorporated in the District plan)

- Shortens the planning cycle

- Simple format, can be conducted quickly in districts, requires no external supervision, and is simple to analyse.

- Effective audit tool

\section{SM RAT}

The SM RAT enables Districts to assess Safe Motherhood service provision:

- Obstetric data (safe deliveries, C-section rate, MMR, IMR)

- Human Resources: Staffing and Training

- Infrastructure: Facilities, Equipment, Supplies and Drugs

- $\quad$ Range of services provided

\section{How is it used?}

The SM RAT comprises a simple-to-enter 10-page questionnaire that is completed at District and Health Facility level. Data is collected from every health facility; the form can be completed in less than two hours. The results are analysed at District level. Carefully planned, the entire exercise, including analysis of the findings, can be completed during supervision activities. Minimal training is required.

\section{What can it do?}

The format of the SM RAT ensures fast and accurate analysis of service provision, and identifies gaps and weaknesses in service provision. District teams can then plan an implementation strategy to improve services. The SM RAT also provides the means to monitor and evaluate the impact of the SM interventions.

The SM RAT can be used in any District. Further developed, the SM RAT could be used to assess all the components of the Kenya Essential Health Package. 